\begin{tabular}{|l|l|}
\hline Postprint Version & 1.0 \\
\hline Journal website & http://www.springerlink.com/content/g76m365n10w46428/ \\
\hline Pubmed link & \\
\hline DOI & $10.1007 / s 12483-011-0020-\mathrm{x}$ \\
\hline
\end{tabular}

This is a NIVEL certified Post Print, more info at http://www.nivel.eu

\title{
Geestelijke gezondheidszorg in de huisartspraktijk: psychiatriseren of normaliseren?
}

\author{
PETER VERHAAK
}

\author{
SUMMARY \\ Mental health care in general practice: Psychiatry or normal \\ care?
}

In 2004 Ormel, Bartel and Nolen (2004) formulated the 'depression paradox': although evidence based interventions for depression have been developed the past 20 years, the prevalence of depression is not decreasing, it is even increasing for certain subgroups.

Different explanations for this paradoxical development have been put forward.

Patients do not look for help. However, part of them do not experience a need for help.

Patients who get help are not treated adequately. However, the more severe the disorder, the larger the odds to get adequate help. Moreover, those not treated according to guidelines have comparable remission rates as those treated adequately.

Patients who receive adequate treatment are not compliant. However, patients are offered treatment that is not their first choice To explain the depression paradox, we propose a new conceptualizing in primary mental health care. A clearer distinction is needed between the larger category of psychological problems, expressions of distress etc., that deserves professional attention and guidance and the smaller category of psychiatric disorder, linked to pathophysiological disturbance and in need for evidence based medicine. DSM-IV criteria are not sufficient to make this distinction.

My research program for the following five years will be aimed at a further clarification of this distinction. Main lines of research are the need for psychological help as the patient perceives it, psychological treatments that avoid treatment within a 'psychiatric' paradigm, unless needed and cooperation between family medicine and specialized mental health care to realize a proper task division between general psychological care and psychiatric care.

\section{INLEIDING}

Psychische stoornissen komen veel voor in de bevolking en onder huisartspatiënten (Alonso et al. 2004; De Graaf, Ten Have \& Van Dorsselaer, 2010, WHO 2004).

Angst en depressie zijn de meest voorkomende. Voor zover mensen hiervoor behandeld worden, geschiedt dat veelal in de huisartspraktijk (Verhaak, Van Beljouw \& Van Dijk, 2010), maar bij veel mensen lijkt angst of depressie niet onderkend te worden en dus krijgen ze daarvoor totaal geen hulp (Wang et al. 2007).

Dit is jammer, want uit gerandomiseerde trials blijkt dat met name depressie goed behandelbaar is met psychologische interventies (Cuijpers, Van Straten, Van Schaik \& Andersson, 2009; Landelijke Stuurgroep Multidisciplinaire Richtlijn 2005), psychofarmaca (Landelijke Stuurgroep Multidisciplinaire Richtlijn 2005) en collaborative care (Katon et al. 1999 ). Behandeling van psychische stoornissen is ook nog eens redelijk kosteneffectief (Gabbard, Lazar, Hornberger \& Spiegel, 1997; Simon et al., 2001) en, om het nog 
mooier te maken, ook preventieve programma's waarmee depressie voorkomen wordt, zijn effectief gebleken (Cuijpers, Van Straten \& Smit, 2005).

Bovenstaande zinsneden zijn min of meer plichtmatige openingszinnen uit wetenschappelijke artikelen over de opsporing en behandeling van psychische problemen in de huisartspraktijk. Het zijn openingszinnen die ikzelf ook gebruik en, zoals hierboven ook geschiedt, ze kunnen gestaafd worden met onderzoeksbevindingen.

Er wordt een 'state of the art' geschetst die tot de conclusie leidt dat mensen met psychische stoornissen effectief kunnen worden opgespoord en behandeld volgens het principe van getrapte zorg: stepped care.

Hiervoor is het nodig dat deze stoornissen in de eerstelijn systematisch worden gesignaleerd en zoveel mogelijk volgens richtlijnen worden behandeld. Heeft dit geen effect dan zullen ze in een volgende stap worden doorverwezen naar meer gespecialiseerde GGZ. Door vroegtijdige signalering van subklinische gevallen van depressie zal het ontstaan van echte stoornissen vaak al kunnen worden voorkomen met een preventieve behandeling en om terugval te voorkomen zal een blijvende surveillance geboden zijn.

Dit is een mooie wereld en misschien is hij wel te mooi om waar te zijn. Al in 2004 spraken Ormel, Bartel en Nolen (2004) van de 'depressie paradox': voor depressie zijn er inderdaad bewezen werkzame behandelingen voorhanden maar zij zagen de afgelopen decennia geen dalende prevalentie van depressie, eerder een toename. Bewezen effectieve behandeling zou de maandprevalentie aan depressie met ongeveer een kwart kunnen reduceren, maar dat gebeurde niet.

Voor bepaalde deelgroepen, jonge vrouwen, mensen met een lagere sociaaleconomische achtergrond, constateerden ze zelfs een toename. Zij zochten de oorzaken van deze paradox met name in het proces van de zorg. Mensen zoeken te weinig hulp, als ze hulp zoeken deugt de behandeling vaak niet, de patiënt draagt door te weinig zelfzorg en een gebrekkige therapietrouw daar ook weinig toe bij en wellicht is het beloop van depressie op langere termijn minder florissant dan trials met een uitkomstmeting na zes maanden voorspiegelen. Ik zal bij al deze argumenten stilstaan.

\section{Mensen zoeken te weinig hulp.}

Het is een feit dat veel mensen wier problemen in de DSM-IV als een psychische stoornis als angst of depressie worden geclassificeerd, daarvoor aangeven geen hulp te willen. Van Beljouw et al.(2010) hebben hierover gegevens uit de NESDA-studie geanalyseerd. In deze studie wordt een grote groep van bijna 750 volwassen patiënten uit huisartspraktijken bij wie een angst stoornis of een depressie is vastgesteld gedurende acht jaar gevolgd. De volgende gegevens hebben betrekking op hun toestand bij het begin van het onderzoek. Ze kwamen tot de volgende bevindingen.

Van alle mensen tussen de 18 en 65 jaar die volgens een gestandaardiseerd diagnostisch interview een angststoornis of een depressieve stoornis hadden, bleek dat ongeveer de helft het half jaar voor het interview contact had gehad daarover met een hulpverlener.

Van degenen die geen contact gehad hadden, vond ongeveer een kwart dat er geen psychisch probleem was, een kwart erkende wel een probleem te hebben maar wilde daarvoor geen behandeling en ongeveer de helft van de onbehandelden gaf aan wel degelijk een behandelbehoefte te hebben.

\section{Mensen worden niet goed behandeld.}

Dat is de volgende verklaring die Ormel en collega's voor de 'depressie paradox' geven.

Ook hierover hebben we in het NESDA-onderzoek geprobeerd uitsluitsel te vinden. Smolders et al. (2009) en Prins (2010) onderzochten de mate waarin huisartsen de NHG-richtlijnen volgden bij de behandeling van die 750 patiënten waarbij een angststoornis of depressie was vastgesteld. Ook onderzochten ze welke patiënt- en huisartskenmerken het volgen van de richtlijnen bevorderden of juist belemmerden. Maar een beperkt deel van de patiënten met angst of depressie werd door de huisarts conform deze richtlijnen behandeld: ongeveer een kwart van de patiënten met een angststoornis, iets meer dan veertig procent van de mensen met een depressie en de helft van de mensen die zowel een angststoornis als een depressie hadden (Smolders et al., 2009). Mensen met uitsluitend een angststoornis hebben een kleinere kans om behandeling volgens de richtlijn te krijgen dan mensen die zowel een angststoornis als een depressie hebben. Laag opgeleiden hebben minder kans op passende behandeling.

Patiënten die aangaven zelf behoefte aan medicatie, counseling of een verwijzing te hebben, krijgen eerder hulp volgens de richtlijnen (Prins et al., 2010). 
Belangrijke factoren aan de kant van de huisarts om zorg conform de richtlijnen te geven zijn diens vertrouwen om met depressie om te gaan en samenwerking met andere GGZ-hulpverleners (Smolders et al., 2010).

In Grafiek 2 zien we hoe de ernst van de depressie is afgenomen van patiënten die volgens de richtlijnen behandeld zijn in vergelijking bij patiënten bij wie dat niet het geval was (Prins, 2010).

We zien in deze grafiek twee belangwekkende zaken.

Ten eerste: patiënten die niet of niet volgens de regels behandeld worden hebben bij aanvang al minder ernstige symptomen. In de tweede plaats: ze vertonen een vergelijkbare mate van herstel.Wanneer we corrigeren voor mogelijk leeftijds-, geslachts- en opleidingsverschillen tussen patiënten en ook de verschillen tussen praktijken en artsen verdisconteren, dan is er zowel voor de goed behandelde als voor de minder goed of niet behandelde groep een significante daling in ernst en die daling is in beide gevallen even groot.

Huisartsen hebben dus de neiging om hun behandeling op de ernstiger gevallen te richten. Maar de minder ernstige gevallen herstellen zonder behandeling even goed als de ernstiger met behandeling.

\section{[GRAFIEK 1, 2]}

Dit is overigens geen nieuw gegeven: Dowrick en Buchan (1995) meldden vijftien jaar geleden al dat patiënten met door de huisarts gediagnosticeerde depressie minder goed herstelden dan patiënten met depressie die de huisarts niet opmerkte. Hij concludeerde dat het feit dat huisarts de diagnose depressie stelt opgevat kan worden als een aanwijzing voor de ernst. David Goldberg (Goldberg, Privett, Ustün, Simon \& Linden, 1998) beschrijft in 1998 een naturalistische studie in 15 landen waarin huisartsen kunnen kiezen of ze depressieve patiënten behandelen met antidepressiva, sedativa, zonder medicatie en een vierde groep waarbij de huisarts de depressie niet opmerkt. De twee groepen met medicatie hebben bij aanvang veel ernstiger symptomen dan de twee andere groepen en dat is aan het einde hetzelfde. Nogmaals: huisartsen pikken de ernstigste gevallen eruit voor behandeling en degenen die de behandeling niet krijgen knappen even goed op.

Ormel et al. (2004) hadden gelijk dat de behandeling vaak niet aan de richtlijn voldoet, maar daarbij hoort de kanttekening dat dat in natuurlijke beloopstudies niet zoveel verschil uitmaakt. Overigens, ook in experimenteel onderzoek waar de behandeling volgens de regelen der kunst wordt uitgevoerd, moeten we vaak vaststellen dat interventies die beproefd zijn in de tweede lijn in de eerste lijn veel minder effect sorteren.

Van Dyck (2007) heeft daar in zijn afscheidsrede als hoogleraar psychiatrie aan de VU uitgebreid over gesproken.

Hij somt een groot aantal recente Nederlandse dissertaties op, waarbij in de tweede lijn beproefde behandelingen in de huisartspraktijk nauwelijks meer effect sorteren dan gebruikelijke zorg. Fournier en collega's publiceerden ongeveer een jaar geleden een meta-analyse over onderzoek van de afgelopen 30 jaar naar antidepressiva, waaruit blijkt dat antidepressiva bij lichte gevallen van depressie, zoals men ze vaak in de eerste lijn aantreft, nauwelijks beter werken dan placebo's.

Bij ernstige gevallen van depressie daarentegen is de werkzaamheid van antidepressiva wel duidelijk aanwezig (Fournier et al. 2010). Al tien jaar geleden ontstond veel beroering toen Kirsch en Sapirstein (1998) meldden dat het placebo-effect het grootste deel van het herstel voor zijn rekening nam. In een reactie hierop gaf Andrews (2001) te kennen dat grote placeboresponsen juist bij depressie gevonden worden, terwijl de placeborespons bij angst kleiner (25-50\%) is en bij schizofrenie nauwelijks wordt aangetroffen. Cuijpers et al. (2009) voerden een meta-analyse uit op de gegevens van 15 gerandomiseerde studies naar het effect van psychologische behandelmethoden in de eerste lijn.

Zijn conclusies zijn belangwekkend voor ons betoog.

Over het geheel genomen blijkt de experimentele behandeling in de eerste lijn wel effectiever dan gebruikelijke zorg door de huisarts, maar het is maar een gering effect. De effectgrootte in deze eerstelijns studies is veel kleiner dan de effectgrootte van vergelijkbare interventies in andere settings. Dit wordt met name beïnvloed door de wijze waarop men patiënten voor de behandeling rekruteert: geschiedt dit door een screeningsinstrument dan is het behandeleffect in de eerste lijn veel kleiner dan in andere settings, worden patiënten die voor behandeling in aanmerking komen door de huisarts aangewezen, dan is het effect groter. 
Conclusie: winst bij eerstelijnsbehandeling is relatief gering, zeker wanneer de huisarts niet van tevoren een schifting aanbrengt.

Ormel et al. (2004) hebben gelijk. Veel patiënten worden niet behandeld voor hun psychische problemen zoals de richtlijnen voorschrijven, maar bij degenen die die gepatenteerde behandeling mislopen maakt het ook niet zo veel uit en bij degenen die het wel krijgen is het effect geringer dan men op basis van tweedelijns onderzoek zou verwachten.

\section{Patiënten die behandeld worden, houden zich niet aan de behandelrichtlijnen.}

Dit is de volgende verklaring van de depressieparadox.

Ook al is de behandeling conform de richtlijnen, dan kan het mislopen omdat patiënten zich niet aan de behandelvoorschriften, veelal met betrekking tot medicatie, houden. Lingam en Scott (2002) rapporteren een mediaan van ruim 50\% van mensen die zich niet goed aan de behandelvoorschriften houden. Dit heeft te maken met bijwerkingen van medicijnen, met het uitblijven van effecten en met misvattingen over medicatie in het algemeen en antidepressiva in het bijzonder.

Een goede huisarts-patiënt relatie kan bijdragen aan betere compliantie.

$\mathrm{Er}$ is echter meer dan alleen verkeerde beeldvorming bij de patiënt. Uit het eerdergenoemde onderzoek op NESDA-data blijkt dat $60 \%$ van patiënten met een DSM-IV classificatie aangeeft geen behoefte te hebben aan medicatie (Prins et al., 2009). Van de mensen die geen behandeling kregen maar dat wel wilden, hadden de meesten behoefte aan informatie of gespreksmatige hulp. Behoefte aan een verwijzing, medicatie, praktische hulp of vaardigheidstraining werden veel minder genoemd (Van Beljouw et al., 2010).Wat krijgen de meeste huisartspatiënten echter? Medicatie, soms samen met counseling; 12\% wordt verwezen, zoals Grafiek 3 laat zien.

Chilvers et al.(2002) stelden al enige jaren geleden in een trial vast dat het effect van gespreksvoering en medicatie niet veel voor elkaar onder doen, maar dat het wel uitmaakt of patiënten de behandeling van hun aanvankelijke voorkeur hadden gekregen. Resumerend: de patiënt moet wel meewerken, maar het maakt uit of zijn preferenties daarbij betrokken worden.

In het voorafgaande zijn meerdere auteurs de revue gepasseerd die erop gewezen hebben dat de daadwerkelijk bereikte resultaten van behandeling van alledaagse psychische problemen in de eerste lijn achterblijven bij de verwachtingen die wetenschappelijk onderzoek gewekt heeft. Ze zijn in grote lijnen eenstemmig over de weg die ingeslagen moet worden. Ormel en collega's (2004) concluderen dat verbetering van signalering, behandeling volgens de richtlijnen, intensivering van zorg voor patiënten die niet reageren op simpele maatregelen en terugvalpreventie de vereisten zijn. Van Dijck (2007) ziet lichtpunten in de opkomst van collaborative care, waarbij de expertise van de SPV en psychiater veel meer in de eerstelijnszorg wordt geïntegreerd. En ook Cuijpers et al. (2005) hebben als eerste aanbeveling dat huisartsen en de GGZspecialisten waarheen ze verwijzen nog meer moeten gaan samenwerken.

Deze oplossingen gaan echter voorbij aan de suggestie die van al deze tegenvallende behandelresultaten van psychische problemen in de eerste lijn ook uitgaat: zijn deze problemen wel vergelijkbaar met de psychische problemen waarvoor de specialistische GGZ effectieve behandelingen heeft te bieden? Alvorens tot mijn oplossingen te komen, wil ik eerst mijn probleemanalyse met u delen.

\section{[GRAFIEK 3]}

\section{Een alternatief verklaringsmodel voor de depressie}

\section{paradox}

Wilson en Cleary (1995) hebben eind vorige eeuw gewezen op de gelaagdheid van het begrip 'gezondheidstoestand', dat op steeds gedetailleerder niveau in beschouwing kan worden genomen. Ik heb de vrijheid genomen hun dimensie vanuit verschillende invalshoeken in te vullen.

Wilson en Cleary (1995) ontwikkelden hun model vanuit het besef dat gezondheid op veel verschillende niveaus gemeten kan worden. Aan het ene uiterste zien we de sociaalwetenschappelijke invalshoek met een globale schatting van de gezondheid van individuen.

Aan het andere uiterste het biologische perspectief, gericht op pathologische lichaamsprocessen. 
Op het meest gedetailleerde niveau wordt gezocht naar afwijkingen op cel- of moleculair niveau. De medisch specialist observeert symptomen op het niveau van organen. Weer een niveau hoger kijkt de huisarts, de verpleeghuisarts of revalidatiearts naar de functionele status van het gehele lichaam: welke beperkingen heeft de patiënt en wat kan hij nog wel. De patiënt ten slotte neemt op basis van een algemeen gevoel van gezondheid of ongezondheid, zijn gezondheidstoestand in ogenschouw.

Op microbiologisch niveau kijken we naar MRIscans van de hersenen, naar de heropname van serotonine of we zoeken naar mutaties in het gen die verantwoordelijk zijn voor bijvoorbeeld schizofrenie. Op het niveau van de zieke organen richt de specialist zich op symptomen en op laboratoriumuitslagen die iets zeggen over de werking van die organen. De medische hulpverlener met een meer generalistische blik onderzoekt op gestandaardiseerde wijze wat de mogelijkheden en beperkingen van de patiënt zijn en op het meest algemene niveau vraagt de patiënt zich af of hij zich lekker voelt of niet.

Dit continuüm van globaal patiëntengevoel tot een vertaling daarvan op het niveau van bloedwaarden en MRI-scans kan ook uitgedrukt worden op het continuüm van ziektegevoel tot gedefinieerde ziekte. Het subjectieve gevoel dat in het Engels wordt uitgedrukt in het woord 'illness' in tegenstelling tot het geobjectiveerde 'disease'. Definiëren we het aan de hand van bevindingen op fysiologisch of pathologisch/ anatomisch niveau dan spreken we over ziekte in de zin van 'disease'. Op dit niveau is de medische wetenschap er de afgelopen 150 jaar in geslaagd ziekten te definiëren, hun ontstaan en beloop te verklaren en succesvolle behandelingen te ontwikkelen. In het beste geval zijn oorzaken, beloop en prognose welomschreven. Het is objectiveerbaar. De tegenpool, 'illness' of ziektegevoel refereert aan subjectieve belevingen die toegeschreven worden aan ziekte, maar waarvan de relatie met lichamelijke afwijkingen nog vastgesteld moet worden (vergelijk Lamberts, 1975). Het ziektegevoel geeft het patiëntenperspectief weer, geobjectiveerde 'ziekte' is de uitdrukking van het professionele perspectief.

Op de onderste rij geef ik aan dat men in de open populatie en in de eerstelijnsgezondheidszorg veelal met 'ziektegevoel' geconfronteerd wordt. In de meer specialistische omgeving krijgt men te maken met klinische manifestaties die zich beter in symptoomdefinities volgens een DSM-IV laten voegen, manifestaties die als stoornis betiteld kunnen worden. De gang van hulp zoeken via huisarts naar gespecialiseerde GGZ in de onderste rij zal door ingewijden herkend worden als het model van Goldberg en Huxley (1992), dat in Groningen met name door het werk van Giel en Ormel (Giel, Koeter, Van de Meer \& Ormel, 1991) de afgelopen 25 jaar bekend is geworden.

Uiteraard is er verband tussen de onderscheiden domeinen, maar ze vallen niet samen, zie Grafiek 4.

\section{[TABEL 1]}

\section{[GRAFIEK 4]}

Behalve dat de overlap tussen op fundamenteel niveau en meer globaal beschreven toestandsbeelden niet volmaakt is, blijkt het globale niveau in een aantal opzichten het specialistische, fundamentele niveau de baas te zijn. Zo is herhaaldelijk vastgesteld dat het gezondheidsgevoel van patiënten een betere voorspeller voor overlijden tien jaar later is, dan nauwkeurige fysiologische metingen (Wilson en Cleary, 1995; Idler, Russell \& Davis, 2000) Mijn hypothese is dat in de gespecialiseerde omgeving, waar men een op ernst geselecteerde populatie bestudeert, waarnemingen op fysiologisch niveau, klinische symptomen, ervaren beperkingen en algemene gezondheidservaring meer samenvallen dan in de omgeving van de eerstelijns gezondheidszorg en de algemene bevolking, waar rijp en groen samenkomen.

Therapieën om angststoornissen en depressie te behandelen zijn ontwikkeld en getest in een specialistische omgeving, op populaties die voldeden aan de criteria voor de ideaaltypische 'disease'.Wanneer dat het geval is, zal de aanwezigheid van klinische symptomen (nodig voor een DSM-IV classificatie) traceerbaar zijn in fysiologische processen in de hersenen en samenvallen met de beperkingen die patiënt heeft en de beleving van de patiënt. In een meer algemene omgeving is dat verband veel minder sterk.

Deze hypothese zou een aantal van de anomalieën hierboven naar voren gebracht, verklaren.

1 Therapieën werken minder goed bij patiënten in de eerste lijn of de open populatie omdat er veel vals positieven zijn. Als men DSM-IV criteria, ontwikkeld in de tweede lijn, gaat toepassen in de eerste lijn dan zullen de symptomen een veel kleinere predictieve waarde hebben, omdat de prevalentie van ernstige depressie veel kleiner is. 
2 Het zou ook verklaren dat een relatief vage nosologische ziektecategorie als 'depressie’ veel gevoeliger lijkt voor placebo-effecten dan een ziektecategorie als schizofrenie met duidelijker aangrijpingspunten in onderliggende fysiologische mechanismen.

3 Het zou verklaren dat in de eerste lijn of algemene bevolking voor een groter deel sprake is van spontaan herstel, ook zonder behandeling conform richtlijnen.

4 En dus verklaart het dat de aangetroffen hulpbehoefte bij mensen met DSM-IV symptomen in de eerste lijn of algemene bevolking kleiner is.

\section{Gevolgen van de alternatieve verklaring}

De implicatie van mijn hypothese is dat er een veel strenger onderscheid gemaakt moet worden tussen patiënten die aan een ernstige psychische stoornis lijden, die we met recht als 'disease' kunnen betitelen, en mensen die bij navraag wel een aantal symptomen noemen maar niet binnen de echte ziektedefinitie vallen. Hierbij is de door de patiënt ervaren lijdensdruk en hulpbehoefte een belangrijke richtsnoer.

Hiermee sluit ik aan bij de traditie van de founding fathers van het Nederlands Huisartsen Genootschap, Frans Huijgen en Jan van Es om de meest toonaangevenden te noemen. Zij wezen erop dat het probleemaanbod in de eerste lijn fundamenteel anders is dan het geselecteerde aanbod dat bij de specialist belandt (Van Es, 1980). Huijgen is degene die er als geen ander op gewezen heeft dat in geval van ziekte het lichamelijke en het psychosociale altijd verweven zijn, zonder dat daarbij onmiddellijk het psychische in de pathologische, psychiatrische sfeer getrokken moet worden (Huijgen, 1978).

De huisarts wordt geconfronteerd met rijp en groen. Hij ziet de hele range van duidelijke gevallen van 'disease'

tot vage symptomen en onlustgevoelens, waarvan de diagnose nog alle kanten uit kan. Een belangrijke taak voor de huisarts is te schiften. Uit het handboek huisartsgeneeskunde van Van Es ken ik het verhaal van de 19e eeuwse Utrechtse hoogleraar interne geneeskunde Talma. Deze maakte in zijn colleges gewag van een in zijn ogen zeer kundige huisarts die slechts twee diagnosen gebruikte: pluis of niet pluis. Pluis betrof alle symptomen van self limiting diseases, niet pluis waren de aandoeningen die zonder ingrijpen een slechte afloop zouden hebben. Huijgen en zijn school ontwikkelde het concept 'preventie van somatische fixatie' (Grol, 1983), waarin gewaarschuwd werd voor een te snelle gerichtheid op somatische symptomen die patiënten uiten, ergo voor een te snelle beslissing in de richting van een mogelijk 'disease'. Mutatis mutandis pleit ik voor terughoudendheid bij psychische symptomen, om deze meteen om te vormen tot een psychiatrische diagnose.

Wanneer men louter symptomen conform de DSM-IV telt, wordt in die gevallen waar symptomatologie niet goed samenvalt met ziektegevoel veel groen tot rijp benoemd, wordt 'illness' ten onrechte 'disease' en eigent de specialist of de basis GGZ zich deze 'gevallen' toe.

Waarbij, zoals betoogd, een substantieel deel geen behandelbehoefte heeft. Van onverdachte huize kan ik Dick Swaab citeren die in zijn boek 'Wij zijn ons Brein' onverkort stelt dat “in drie kwart van de gevallen ......[dat mensen antidepressiva slikken] worden deze middelen gegeven aan iemand die weliswaar in de put zit, maar geen zware depressie heeft”(Swaab, 2010, p. 155).

Oftewel: er zijn enige beperkingen, de nodige symptomen zijn wellicht aanwezig, maar op het biologische vlak is er onvoldoende aanleiding om van een zware depressie te spreken die als ziekte behandeld moet worden Twee belangrijke taken liggen hier voor de huisarts.

In de eerste plaats, het scheiden van pluis en niet pluis.

En in de tweede plaats, degenen die wel hulp zoeken maar niet als depressief in engere zin (of als pathologisch angstig) gediagnosticeerd moeten worden, op zodanige wijze tegemoet treden dat men zich erkend voelt en niet vanwege het niet erkend worden alsnog in contraproductief ziektegedrag vervalt. Aan de wijze waarop dat in de huisartspraktijk kan geschieden, wil ik het laatste deel van mijn betoog wijden.

Waar het gaat om het onderscheid tussen patiënten met een ernstige psychische aandoening en patiënten met levensproblemen die begeleiding behoeven, wil ik wijzen op de door Terluin ontwikkelde vierdimensionale klachtenlijst (4DKL) (Terluin et al.2009). Deze lijst probeert onderscheid te maken tussen mensen met min of meer normale stressreacties en mensen met een echte stoornis, angst of depressie. Mensen met een stoornis hebben ook stresssymptomen, maar andersom hebben de meeste mensen met stresssymptomen geen stoornis in de engere zin. Met de 4DKL worden de twee groepen van elkaar onderscheiden.

Kenmerkend voor het gebruik van deze vragenlijst is dat het niet zozeer een screener moet zijn, waarmee je aan de uitslag afleest of de patiënt 'psychische koorts' heeft, maar veel meer een gespreksagenda voor 
arts en patiënt op basis waarvan ze het gesprek kunnen aangaan en de arts kan nagaan of hij een psychische stoornis in engere zin uit kan sluiten. Een gesprek dat wellicht gedelegeerd kan worden, daarover dadelijk meer.

Waar het gaat om behandeling pleiten Bensing en Van Dulmen (Raad voor Gezondheidsonderzoek, 2000) al jaren voor het meer serieus nemen van de mogelijk helende werking van het placebo-effect, dat nu voornamelijk gezien wordt als spelbreker bij het onderzoek naar antidepressiva. Ik memoreerde al dat juist bij mensen met een lichte depressie de placebowerking het meest van de werkzaamheid verklaart. (Fournier et al, 2010). Bensing en Verheul (2010) geven in hun review over de rol van communicatie bij placeboeffecten aan dat de meest plausibele mechanismes achter het placebo-effect conditionering, oproepen van verwachtingen en reductie van angst en stress zijn. Het zijn juist deze middelen die de huisarts kan inzetten om in de hulpbehoefte van patiënten op psychisch gebied te voorzien, zonder ze tot de volksziekte 'depressie' te veroordelen. Al veertig jaar geleden bepleitte Dokter (1967) het belang van de persoon van de huisarts bij het genezingsproces.

Johnston et al. (2007) geven aan dat veel huisartspatiënten met depressieve klachten een weerstand ervaren tegen een benadering vanuit een ziektemodel. Ze zien hun toestand niet als een ziekte maar als een omstandigheid waarmee ze van dag tot dag moeten leren leven. Praten en begrip van een professional helpen daarbij. Daarbij verdient de benadering van onverklaarde lichamelijke klachten, die door Dowrick, Ring, Humphris en Salmon (2004) ontwikkeld is, aandacht: men moet deze klachten niet negeren, ook niet wegwuiven met de mededeling dat onderzoek geen afwijkingen aantoont en dat men zich dus geen zorgen moet maken, maar men moet samen met de patiënt oplossingen of verklaringen vinden, oplossingen die geworteld zijn in de belevingswereld van de patiënt. Ik noemde reeds het door Huijgen en Grol ontworpen programma 'preventie van somatische fixatie'. Patiënten met steeds terugkomende lichamelijke hulpvragen waarbij geen sprake is van ernstige ziekte (opnieuw: er is een grote discrepantie tussen 'illness' en 'disease') moeten serieus genomen worden, niet afgewezen maar ook niet bevestigd in hun angst voor een ziekte. Ik pleit nu voor dezelfde houding ten opzichte van psychisch onwelbevinden, om 'psychische fixatie' te voorkomen.

En dergelijke preventie is belangrijk, in geval van patiënten die geen psychische stoornis in engere zin hebben, die in de categorie 'groen' vallen, waarbij meer sprake is van ziektegevoel dan van psychische stoornis in fysiologische of klinische zin. Een diagnose depressie leidt er namelijk wel toe dat zowel patiënten als hun omgeving zich gaan gedragen naar die diagnose. Die diagnose krijgt een onafhankelijk bestaan. De patiënt is overgeleverd aan een onafhankelijke dreiging van buiten en moet afwachten of de medicatie of andere therapie het de baas zal worden.Wanneer dit vervolgens niet werkt, zal het gevoel van machteloosheid alleen toenemen.

Wanneer het wel werkt is het de vraag wanneer de patiënt weer zonder kan.

De rol van de huisarts als vertrouwde hulpverlener blijft op deze wijze cruciaal. Uiteraard niet zonder dat er sprake is van ondersteuning binnen de huisartsvoorziening, door praktijkondersteuners, en binnen de eerste lijn, wat wellicht binnen afzienbare tijd bekend zal staan als basis GGZ. Maar ook in dit verband wil ik pleiten voor een terughoudende houding ten aanzien van voor de hand liggende psychische diagnoses. De huisarts kan ondersteund worden door een POH-GGZ (praktijkondersteuner huisartsenzorg GGZ) die met de patiënt gesprekken voert om samen met de patiënt te analyseren wat hem dwars zit.Wanneer de POH-GGZ echter begint met een aantal screeningslijsten op depressie, angst en somatisatiestoornis af te nemen, wordt de patiënt al benaderd op het niveau van 'disease', terwijl eerst bezien moet worden welke betekenis zijn gevoelens van 'illness' hebben. Is er echt sprake van 'disease', een psychische stoornis, dan is de basis GGZ, bijvoorbeeld verricht door eerstelijnspsychologen of SPV-en de aangewezen weg. Interessante onderzoeksvraag is dan vervolgens tot welke mate van ernst deze basis GGZ met kortdurende behandeling psychische problematiek aankan, en waar verwijzing naar de echte specialist geïndiceerd is.

\section{Mijn onderzoeksprogramma}

Hiermee is in grote lijnen de thematiek van mijn onderzoeksprogramma de komende jaren geschetst. Dit programma zal zich op drie hoofdlijnen richten: 1 Hulp zoeken en hulpbehoeftes van patiënten.

- Welke kenmerken van patiënten leiden tot hulp zoeken? - Wat zijn behandelvoorkeuren van patiënten onder welke omstandigheden? - Op zoek naar een betere definitie dan DSM-IV criteria voor een 'psychisch ziekte in engere zin’, waarvoor behandeling in GGZ-perspectief geboden is. 
Verhaak, P.F.M. Geestelijke gezondheidszorg in de huisartspraktijk: psychiatriseren of normaliseren? Psychologie \& Gezondheid: 2011, 39(2), 94-103

2 Behandeling van psychische problemen binnen de huisartsvoorziening - Onderzoek naar mogelijkheden om bij symptomen van depressieve aard deze op nietpsychiatriserende wijze te reduceren, bijvoorbeeld door tegengaan van sociale isolatie en activering.

- Onderzoek naar zinnige begeleidingsmethoden voor psychische problemen in de huisartsensetting, zonder deze te 'psychiatriseren'.

- Experimentele placebo-interventies in de huisartspraktijk.

3 De samenwerking en taakafbakening tussen huisarts en basis GGZ - Onderzoek naar inzet van de praktijkondersteuner huisartsenzorg. Nagaan in welke mate de inzet van praktijkondersteuners leidt tot het voorkomen van 'psychische fixatie' en op welke wijze dat voorkomen kan worden.

- Onderzoek naar preferenties van patiënten inzake taakdelegatie en overgang naar basis GGZ.

- Onderzoek naar de vereiste omschakeling van huisartsenzorg naar basis-GGZ en de organisatorische voorwaarden hiervoor.

Gezien de algemene nadruk van de vakgroep, zal dit onderzoek met name worden uitgevoerd onder kinderen en ouderen.

Met de bestudering van deze thema's hoop ik de komende jaren mijn bijdrage te leveren aan het onderzoek binnen de afdeling huisartsgeneeskunde, in het vaste voornemen om dat te doen in samenwerking met iedere groep binnen en de buiten de universiteit die de geestelijke gezondheidszorg in het algemeen en de eerstelijns geestelijke gezondheidszorg in het bijzonder een warm hart toedraagt.

\section{NOTEN}

1. Tekst in verkorte vorm uitgesproken tijdens de oratie van prof. dr.

Peter F.M. Verhaak bij de aanvaarding van het ambt van bijzonder hoogleraar Geestelijke gezondheidszorg in de huisartsvoorziening aan de faculteit der MedischeWetenschappen van de Rijksuniversiteit Groningen

\section{LITERATUUR}

Alonso, J., Angermeyer, M.C., Bernert, S., Bruffaerts, R., Brugha, T.S., Bryson, H. et al. (2004). Prevalence of mental disorders in Europe: results from the European Study of the Epidemiology of Mental Disorders (ESEMeD) project. Acta Psychiatrica Scandinavica,

109(s420), 21-27.

Andrews, G. (2001). Placebo response in depression: bane of research, boon to therapy. British Journal of Psychiatry, 178, 192-194.

Beljouw, I. van, Verhaak, P., Prins, M., Cuijpers, P., Penninx, B., \& Bensing, J. (2010). Reasons and determinants for not receiving treatment for common mental disorders. Psychiatric Services, 61, 250-257.

Bensing, J.M., \& Verheul,W. (2010). The silent healer: the role of communication in placebo effects. Patient Education and Counseling,

80, 293-299.

Chilvers, C., Dewey, M., Fielding, K., Gretton, V., Miller, P., Palmer, B, et al. (2001). Antidepressant drugs and generic counselling for treatment of major depression in primary care: randomized trial with patient preference arms. BMJ, 322, 772-775.

Cuijpers, P., Straten, A. van, \& Smit, F. (2005). Preventing the incidence of new cases of mental disorders. A meta-analytic review.

Journal of Nervous and Mental Disease, 193, 119-125.

Cuijpers, P., Straten, A.van, Schaik, A. van, \& Andersson, G. (2009).

Psychological treatment of depression in primary care: a metaanalysis.

British Journal of General Practice, 59, e Dokter, H.J. (1967). De ontwikkeling van de arts-patiënt relatie in de huisartsgeneeskunst. Huisarts enWetenschap, 10, 142-145.

Dowrick, C., \& Buchan, I. (1995). Twelve month outcome of depression in general practice: does detection or disclosure make a difference? BMJ, 311, 1274-1276.

Dowrick, C.F., Ring, A., Humphris, G.M., \& Salmon, P. (2004).

Normalisation of unexplained symptoms by general practitioners: a functional typology. British Journal of

General Practice, 54,

165-170.

Dyck, R. van (2007). GGZ in de eerste en tweede lijn: de symptomen 
Verhaak, P.F.M. Geestelijke gezondheidszorg in de huisartspraktijk: psychiatriseren of normaliseren? Psychologie \& Gezondheid: 2011, 39(2), 94-103

voorbij? Amsterdam: Vrije Universiteit Amsterdam.

Es, J.C. van (1980). Patiënt en huisarts. Een leerboek huisartsgeneeskunde.

Utrecht: Bohn Scheltema \& Holkema.

Fournier, J.C., DuRubeis, R.J., Hollon, S.D., Dimidjian, S., Amsterdam, J.D., Shelton, R.C. et al. (2010).

Antidepressant drug effects and depression severity. JAMA, 303, 47-53.

Gabbard, G.O., Lazar, S.G., Hornberger, J., \& Spiegel, D. (1997). The economic impact of psychotherapy:

a review. American Journal of

Psychiatry, 154, 147-155.

Giel, R., Koeter, M.W.J., Meer, K. van de, \& Ormel, J. (1991). De filters in het model van Goldberg en

Huxley in de praktijk. Huisarts \&

Wetenschap, 34, 164-169.

Goldberg, D., \& Huxley, P. 1992). Common mental disorders. London: Routledge.

Goldberg, D., Privett, M., Ustün, T..B., Simon, G., \& Linden, M.

(1998). The effects of detection and treatment of depression on the outcome of major depression in primary

care: a naturalistic study in 15 cities. British Journal of General Practice, 48, 1840- 1844.

Graaf, R. de, Have, M. ten, \& Dorsselaer, S. van (2010). De psychische

gezondheid van de Nederlandse bevolking. NEMESIS-2, opzet

en eerste resultaten. Utrecht: Trimbos- instituut.

Grol, R.P.T.M. (red.) (1983). Huisarts en somatische fixatie. Utrecht/ Antwerpen: Bohn Scheltema \&

Holkema.

Huijgen, F.J.A. (1978). Family Medicine. The medical history of families.

Nijmegen: Dekker \& Van de Vegt.

Idler, E.L., Russell, L.B., \& Davis, D. (1992). Survival, functional limitations and self rated health in the

NHANES I Epidemiological follow-up study. American Journal of Epidemiology, 152,

874-883.

Johnston, O., Kumar, S., Kendall, K., Peveler, R., Gabbay, J., \& Kendrick, T. (2007). Qualitative study of depression management in primary care: GP and patient goals, and the value of listening.

British Journal of General Practice, 57, 872-879.

Katon,W,, VonKorff, M., Lin, E., Simon, G.,Walker, E., Unützer, J. et al. (1999). Stepped collaborative care

for primary care patients with persistent symptoms of depression. A randomized trial.

Archives of General Psychiatry, 56, 1109-1113.

Kirsch, I., \& Sapirstein, G. (1998). Listening to prozac but hearing placebo: a meta-analysis of antidepressan medication. Prevention

\& Treatment 1998; 1 http://journals.apa.org/pt/prevention/ volume1/pre0010002a.html Lamberts, H. (1975).

Probleemgedrag in de eerste lijn. Huisarts \&

Wetenschap, 18, 492-502.

Landelijke Stuurgroep Multidisciplinaire Richtlijnontwikkeling (2005). Multidisciplinaire richtlijn Depressie.

Utrecht: Trimbosinstituut.

Lingam, R., \& Scott, J. (2002). Treatment non-adherence in affective disorder. Acta Psychiatrica

Scandinavica, 105, 164-172.

Ormel, J., Bartel, M., \& Nolen,W.A. (2004). De depressieparadox: werkzame behandelingen, maar geen dalende prevalentie.

Oorzaken en beleidsaanbevelingen. Tijdschrift voor Psychiatrie,

46, 237-246.

Pigott, H.E., Leventhal, A.M., Alter, G.S., \& Boren, J.B. (2010).

Efficacy and effectiveness of antidepressants: current status of research. Psychotherapy and

Psychosomatics, 79, 267-279.

Prins, M.A. (2010). Mental health care from the patient's perspective.

A study of patients with anxiety and depression in general practice.

Thesis Universiteit Utrecht, Utrecht: NIVEL.

Prins, M.A., Verhaak, P.F.M., Meer, K. van der, Penninx, B.W.J.H., \& Bensing, J.M. (2009). Primary care patients with anxiety and depression: need for care from the patient's perspective. Journal

of Affective Disorders, 119, 163-171.

Prins, M.A., Verhaak, P.F.M., Smolders, M., Laurant, M.G.H., Meer, K. van der, Spreeuwenberg, P. et al.

(2010). Patient factors associated with guideline-concordant treatment of anxiety and depression in

primary care. Journal of General and Internal Medicine,

$25,648-655$.

Raad voor Gezondheidsonderzoek (2000). Contextwerking in de geneeskunde. Den Haag: RGO.

Simon, G.E., Katon,W.J., VonKorff, M., Unützer, J., Lin, E.H.,Walker, E.A. et al. (2001). Cost-effectiveness

of a collaborative care program for primary care patients with persistent depression. 
Verhaak, P.F.M. Geestelijke gezondheidszorg in de huisartspraktijk: psychiatriseren of normaliseren? Psychologie \& Gezondheid: 2011, 39(2), 94-103

American Journal of Psychiatry, 158, 1638-1644.

Smolders, M., Laurant, M.G.H., Verhaak, P.F.M., Prins, M.A., Marwijk, H.W.J., Penninx, B.W.J.H. et al. (2009). Adherence to evidence-based guidelines for depression and anxiety disorders is associated with recording of the diagnosis. General Hospital

Psychiatry, 31, 460-469.

Smolders, M., Laurant, M.G.H., Verhaak, P.F.M., Prins, M.A., Marwijk, H.W.J., Penninx, B.W.J.H. et al. (2010). Which physician and practice characteristics are associated with adherence to evidence-based guidelines for depressive and anxiety disorders.

Medical Care, 48, 240-248.

Swaab, D. (2010). Wij zijn ons brein. Van baarmoeder tot Alzheimer.

Amsterdam/Antwerpen: Uitgeverij Contact.

Terluin, B., Brouwers, E.P.M., Marwijk, H.W.J., Verhaak, P.F.M., \& Horst, H.E. van der. (2009). Detecting depressive and anxiety disorders in distressed patients in primary care; comparative diagnostic accuracy of the four-dimensional symptom questionnaire (4DSQ) and the Hospital Anxiety and Depression Scale (HADS). BMC Family Practice 10:58:doi:10.1 186/1471-2296-10- 58.

Verhaak, P.F.M., Beljouw, I.M.J. van, \& Dijk, C.E. van (2010). Beleidsonderzoek

GGZ: ondersteunende analyses. www.nivel.nl: NIVEL.

Wang, P.S., Aguilar-Gaxiola, S., Alonso, J., Angermeyer, M.C., Borges, G., Bromet, E.J. et al. (2007). Use of mental health services for anxiety, mood, and substance disorders in 17 countries in the WHO world mental health surveys. Lancet, 370, 807-808.

WHOWorld Mental Health Survey Consortium (2004). Prevalence, severity and unmet need for treatment of mental disorders in the world health organization world mental health surveys. JAMA,

291, 2581-2590.

Wilson, I.B., \& Cleary, P.D. (1995). Linking clinical variables with health-related quality of life. JAMA, 273, 59-65.

\section{GRAFIEKEN EN TABELLEN}

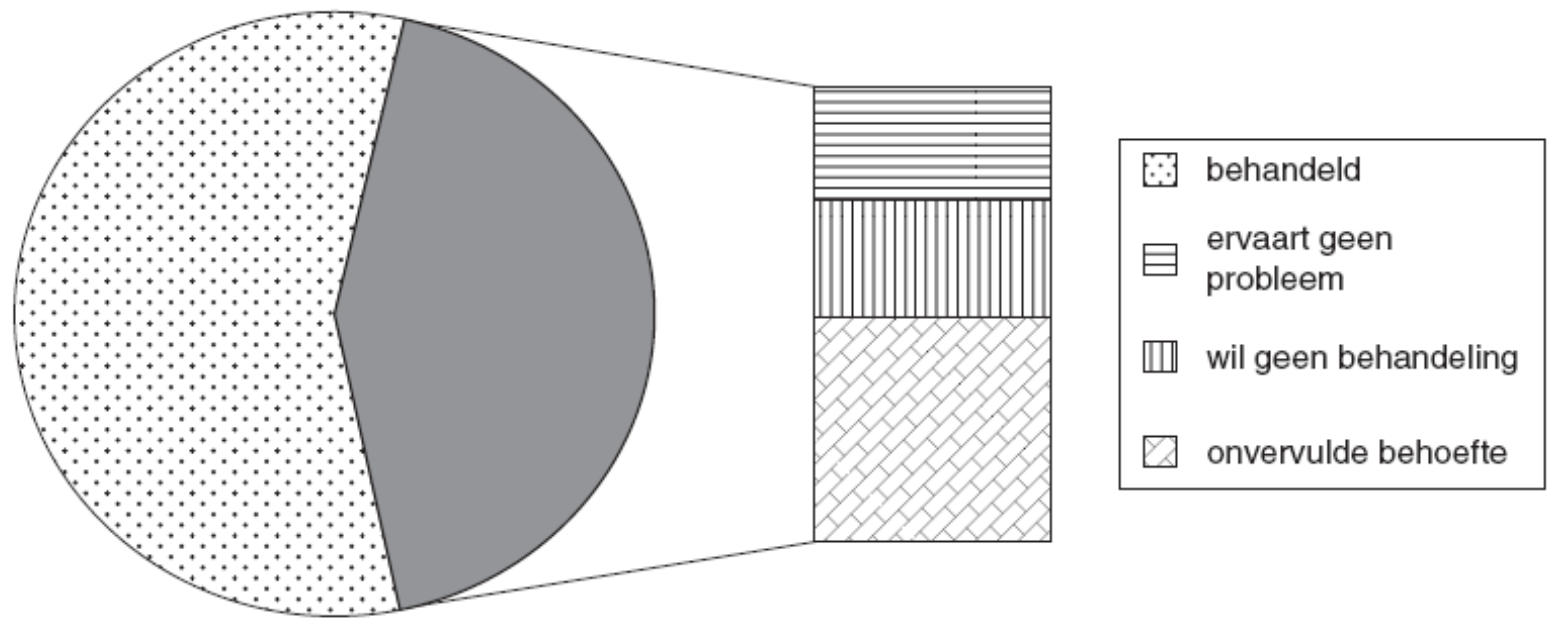

Grafiek 1. Behandeling en behandelbehoefte bij 743 mensen met een DSM-IV diagnose angst of depressie. Bron: Van Beljouw et.al., 2010 
Verhaak, P.F.M. Geestelijke gezondheidszorg in de huisartspraktijk: psychiatriseren of normaliseren? Psychologie \& Gezondheid: 2011, 39(2), 94-103

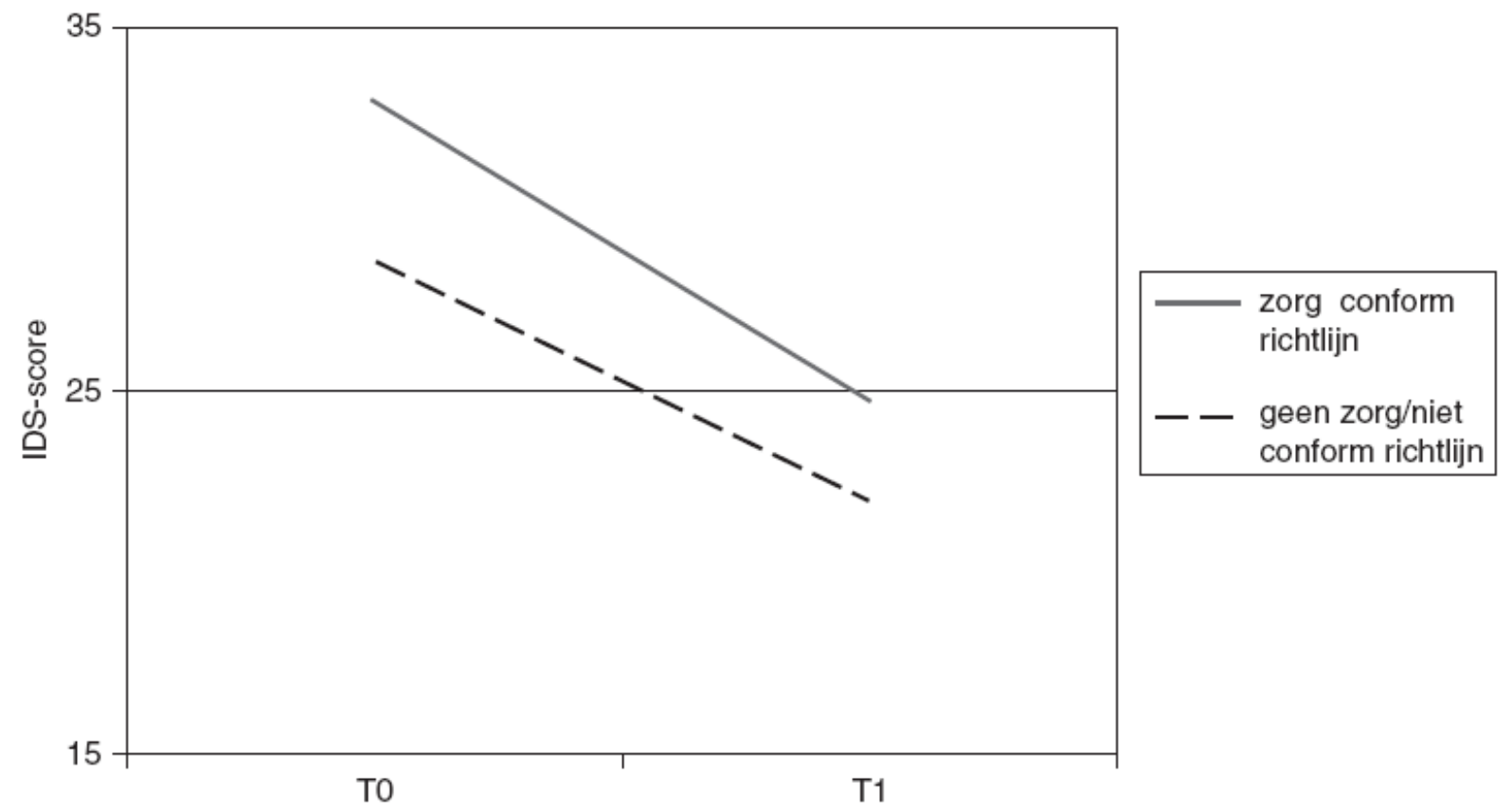

Grafiek 2. Depressie: ernst van depressie bij inclusie en na 1 jaar bij zorg conform richtlijnen en ontbrekende zorg. Bron: Prins, 2010

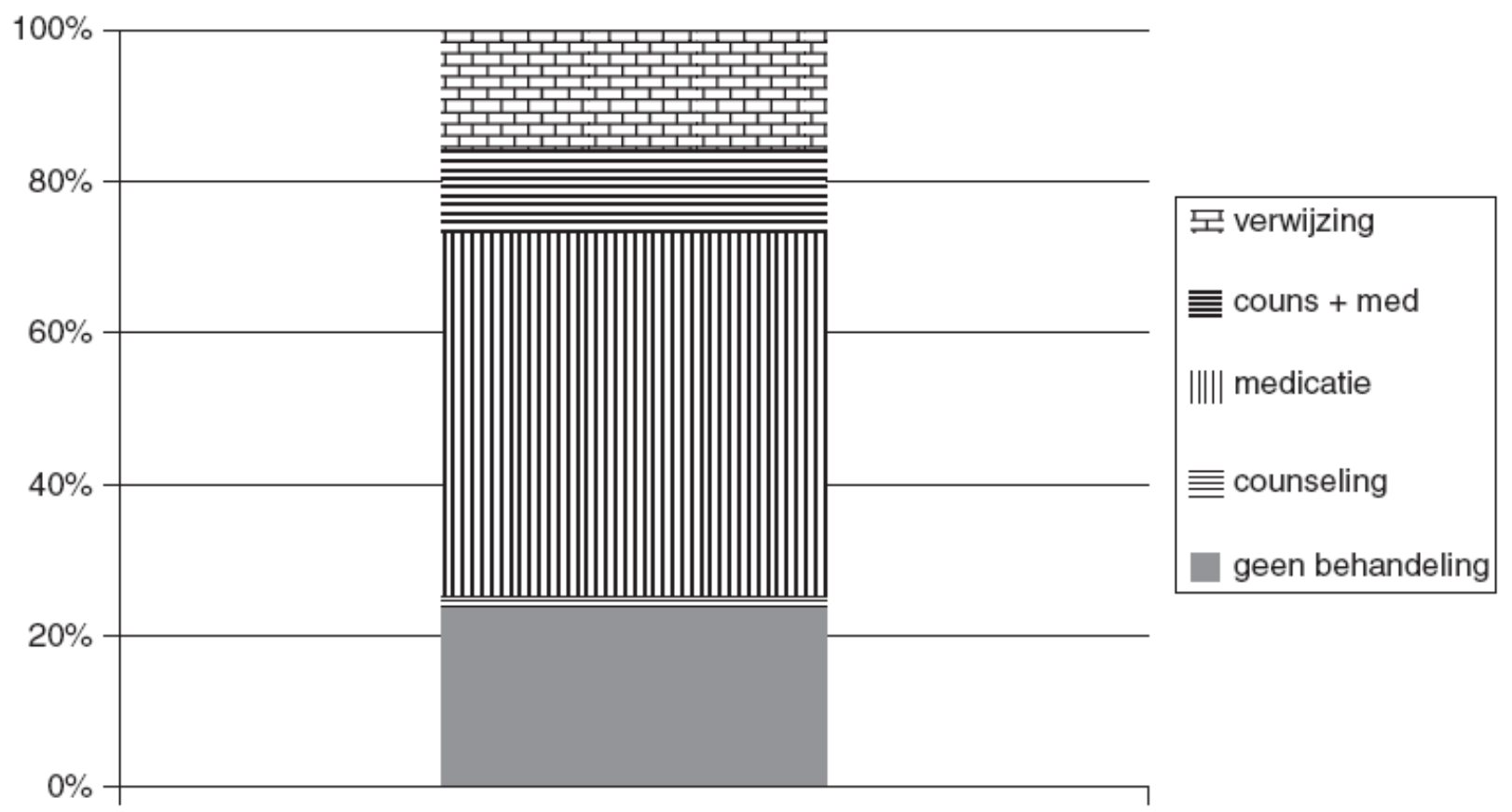

Grafiek 3. Behandelcombinaties in huisartspraktijk bij psychische stoornissen (2008). Bron: LINH, 2008 
Verhaak, P.F.M. Geestelijke gezondheidszorg in de huisartspraktijk: psychiatriseren of normaliseren? Psychologie \& Gezondheid: 2011, 39(2), 94-103

Tabel 1. Model gezondheidstoestand

\begin{tabular}{|c|c|c|c|c|}
\hline $\begin{array}{l}\text { Niveau van observatie } \\
\text { (Wilson and Cleary, } \\
\text { 1995): }\end{array}$ & $\begin{array}{l}\text { Algemeen } \\
\text { gezondheidsgevoel }\end{array}$ & $\begin{array}{l}\text { Functionele status } \\
\text { (beperkingen) }\end{array}$ & Organen & Cel/Moleculair \\
\hline $\begin{array}{l}\text { Wetenschappelijke } \\
\text { invalshoek: }\end{array}$ & $\begin{array}{l}\text { Sociaal- } \\
\text { wetenschappelijk }\end{array}$ & Huisartsgeneeskunde & $\begin{array}{l}\text { Klinische praktijk } \\
\text { Epidemiologie }\end{array}$ & Biologisch/(Patho)fysiologisch \\
\hline Operationalisering: & $\begin{array}{l}\text { Evaluatie door de } \\
\text { patiënt }\end{array}$ & $\begin{array}{l}\text { Gestandaardiseerd } \\
\text { vastleggen wat patiënt } \\
\text { fysiek en mentaal kan }\end{array}$ & $\begin{array}{l}\text { Symptomen: } \\
\text { DSM-IV-classificatie }\end{array}$ & $\begin{array}{l}\text { Brein } \\
\text { Serotonine - heropname } \\
\text { Genen }\end{array}$ \\
\hline & \multicolumn{4}{|c|}{ Illness/Ziektegevoel $\longrightarrow$ Disease/Ziekte/Stoornis } \\
\hline & \multicolumn{4}{|c|}{ Patiëntenperspectief $\longrightarrow$ Professioneel perspectief } \\
\hline Zorgniveau: & Open populatie & $\begin{array}{l}\text { Eerstelijn } \\
\text { Huisarts } \\
\text { (eerstelijnspsycholoog) }\end{array}$ & $\begin{array}{l}\text { Tweedelijn } \\
\text { Ziekenhuis; GGZ- } \\
\text { instelling/psychiater }\end{array}$ & $\begin{array}{l}\text { Fundamenteel onderzoek } \\
\text { Pathofysiologie } \\
\text { Genetica }\end{array}$ \\
\hline
\end{tabular}

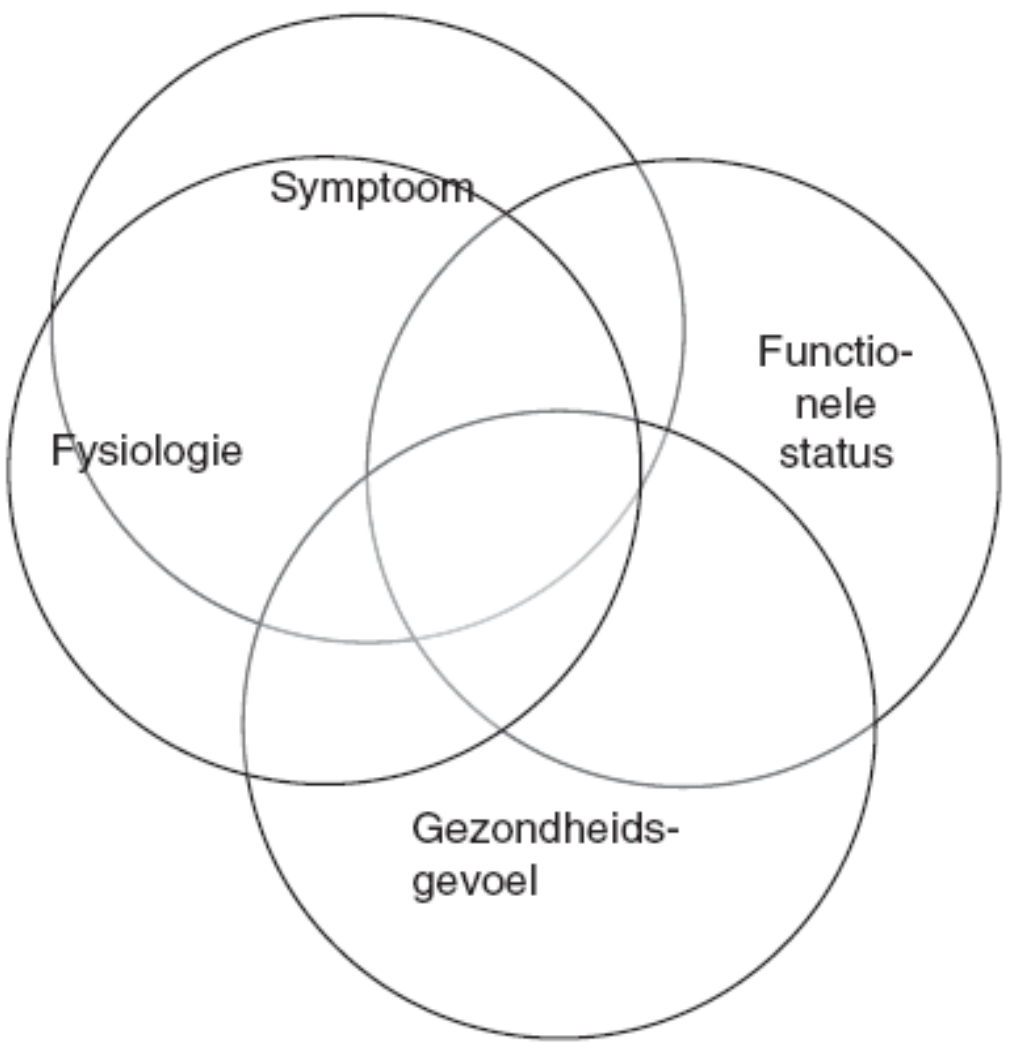

Grafiek 4. Mogelijke overlap tussen fysiologie, symptomen, functio-

nele status en gezondheidsgevoel 